\title{
CFD Numerical Simulation for Intake Flow Field Design and Effects on Combustion and Emissions of DI Diesel Engine
}

\author{
Balaji M, Hemachandra Reddy K
}

\begin{abstract}
The article takes a gander at inevitable results of logical leisure with whirl enhancing modifications on a right away Injection diesel engine. 4 holes at a diversion over every chamber with estimations of the outlet start from 2, 2.five, 3 and $3.5 \mathrm{~mm}$ are through within the chamber with affordable tendency concerning the chamber center factor Numerical guesses are the first-class change to provide clean enduring of the fluid circulate wonder in a DI Diesel Engine. outcomes discover that the unessential beginning of two.five $\mathrm{mm}$ (2nd) bypass on an unequalled begin and excessive weight. Spin development just motor vitality massiveness increment with the changing starting widths. The chamber with 2.five mm establishing make a most vital execution improvement while the chambers with excessive broadness than second hole bypass on a to a few diploma chop down execution. whilst the development in partition transversely over develops the move discipline characteristics like spin, the execution decays beyond 2. five $\mathrm{mm}$. considering the execution attitude an ensuing hole gives improved ingesting and finally most outrageous load for the proportional gas implanted. alternate ultimate holes have to a few diploma more fiery debris launch. in view that numerical results exhibited that ensuing hole offers a transcendent. Of all of the splendid numerical modifications the resultant chamber gives stepped forward presentation and lessens the fee and dreary experimentation tests.

Index Terms: Computational Fluid Dynamics, DI Diesel Engine, Swirl motion, Star CCM, Tangential holes.
\end{abstract}

\section{INTRODUCTION}

Ecological pollution as a result of chamber head have stream in advancing a whole deal in perspective on the expedient industrialization and related expansion in transportation fundamental utilizing chamber head as top quality verdure. The fuel engines rule the non-open transportation divisions however the diesel engines overpower the cash related transportation fragment. By and by a days there may be a business focus driven research style inside the course of to use diesel motors despite for non-open transportation which circuits explorer motors. that is so a result of reality diesel engines are comprehensively seen for their warm adequacy and lower $\mathrm{CO}$ and $\mathrm{HC}$ spread. in any case they have an issue of better particulate and NOx overflowing. The NOx and red hot garbage trade off is an issue that dependably influenced the sort of diesel engines. enormous asks generally were spoken to on the improvement of imbuement methodology, duplicating chamber structures, gas association frameworks and after-fix structures to adjust to the issues of execution, execution and discharge. For an impelled execution of DI diesel engine the

Revised Manuscript Received on April 12, 2019.

Balaji M, Research Scholar, JNTUA, Anantapur,A.P, India (aebalu@gmail.com)

Dr. Hemachandra Reddy K, Professor, Department of ME, JNTUAAnantapur, A.P, India. embedded gas needs to expedient vanish and shape an ignitable mix at grouped locales of the expending chamber. for successfully benefit, diffusive expending should be as quick as can be typical underneath the events. for the reason that diesel automobiles guarantee a stores shorter quality for the blended globules to combo and vanish, the improvement subject basically due to the truth the drop degree picks the gainfulness of devouring. this may be performed through frameworks: a) with the guide of using a power injector, b) by methods for modification of the start chamber geometry with unequivocal bowl geometries to build up the spin and thus agitating impact. The basic need requires extra hardware and further parasitic calamities. other than the mounting issues with the present low speed mechanical implantation framework require colossal exchange inside the fuel circuit. accordingly a predominant open entryway is improve the unsettling influence by methods for techniques for higher chamber made squish and turn. Air development inside the motor barrel anticipate an essential interest, and that they in a general sense influence the expending wonderful. Turn is the extraordinary air advancement winning in a DI diesel motor and relying on the geometrical plans of the bowl, the turn improvement is seen inside the motor. different specialists have investigated the impacts of bowl geometry at the start. regardless, the moment subphysical frameworks like exacerbation, fuel globules intrusion in the begin chamber, its dispersal may be unimaginably extraordinary gotten a handle on through technique for both with the accommodating resource of over the top non intruding methodology like PDV. The computational liquid earth shattering contraption gives a more affordable theoretical comprehension around the ideal frameworks for spread strategy and it's far assistance. With the presentation of extraordinary weight imbuement framework the begin capacity has stimulated in perspective on higher blending of fuel and air. With the presentation of adjusted chamber like torroidal, re-hopeful there's a possibility of impinging at the dividers. a couple of bosses have proposed impinging showers as giving predominant outcomes. Unevenness is key for talented mixing, vanishing and spread of permeated fuel dabs. alterations of chamber like presentation of digressively entered scores may besides in like way expand turn air advancement by methods for technique for empowering air to path by methods for the openings amidst the give up extents of strain methodology and growth blending. The geometry of the chamber bowl 
may be proposed to supply a squish and turning interest which can redesign the fuel/air mix before the begin occurs. two or three past numerical examinations imparts that NOx can be reduced through changing the bowl conviction. a few going before studies use multi zone models to are anticipating the shower spin association. on this work six digressive openings with penchants of hundred to the dimension three hundred to the vertical are exhausted inside the bowl of the chamber. The aftereffects of CFD reenactments on a DI diesel engine with changed chambers are equipped. Advances in period of CFD and in numerical showing and the extraordinary overall execution of $\mathrm{pc}$ systems, have made feasible the all out showing of the in chamber glide. Exhibiting augmentations studies and perception of the whirl, broadened speed, and roughness powers fields inside the get together of IC engine.

\section{NUMERICAL PLAN AND SHOWING DELINEATION}

For the present appraisal a financially open CFD code immense name-CCM+ is completed, which is in structure for loosening up entrapped 3 dimensional pass which merges the effect of harsh shear, divider impacts, warm trade and wild begin. The advancement and expending way may be appeared explaining a hard and fast relationship of Navier Stokes situation, all things considered with province of US which is Direct Numerical Simulation. contemplating it's miles costly and requires a colossal measure of structure resources a streamlined Reynolds Averaged Navier Stokes models. the ones numerical structures consolidate the essential at an early stage and impediment circumstance for the graduation of the connection.

\subsection{Spray showing:}

The convincing and mind boggling try of a diesel motor is commonly subject to it's fuel imbuement framework. CFD mechanical congregations help better comprehension of all the all the more empowering begin thoughts. Sprinkle can be depicted as a complex multiscale swirling way wherein the solid and scattered measurement interface with every one of a kind. there can be a focal fluid region inside the focal region of a dash. The streamlined relationship of makes frailties which finally ends up inside the improvement of fluid sheets of tendons which on in like manner joint exertion with steady medium air, makes progressively small spots. The implantation speed i.e the speed of the fluid gas as it leaves the spout and enters the expending chambers is the most outrageous essential parameter in wash matter. in this canvases the a hit gush models is finished for expecting the implantation speed. The volumetric improvement rate through the injector $\mathrm{Q}$, is foreseen through the going with Equation (1):

$$
Q=c_{d} A_{o} \sqrt{\frac{2}{\rho_{d}} \Delta p}
$$

where $c_{d}$ is the discharge coefficient, $\rho_{d}$ the liquid fuel density and $\Delta p$ the injector pressure drop. Then the actual velocity $v_{c h}$ is given by the equation

$$
v_{c h}=\frac{Q}{A_{0} r_{c h}}
$$

where $r_{c h}$, the proportion of the real jet cross-sectional region at the nozzle opening way out and the geometrical segment zone $A_{0}$, is determined from

$$
r_{c h}=\frac{2 c_{d}^{2} r_{c}^{2}}{r_{c}^{2}+2 r_{c} c_{d}^{2}-c_{d}^{2}}
$$

Atomization is appeared through Huh's atomization show. The central structures are the fuel inaction and the inward unpleasantness stresses made inside the spout. The unevenness made inside the spout taking off produces starting unsettling influence at the fly surface while it leaves the partition. while the aggravations have completed a specific length, they increase exponentially by methods for weight powers prompted by methods for relationship with the consolidating gas surface, until the point even as these inconveniences create as pulled over from the stream into floor as globules. Spout exacerbation and spoil, floor wave headway pick the relationship of specks. what's more the unit of globules character displayed through Reitz-Diwakar appear. As in endeavor with this interpretation speck separation due to streamlined powers which make percent parcel and stripping division association. \%. separation happens even as the non-uniform weight subject over the touch makes it increase inside the low weight wake region and as time goes on go to pot while the floor strain powers are persevere. The stripping separation happen when the fluid is sheared or took from the dab surface. Pack division happen at a straightforward Weber collection

$$
W e=\frac{\rho\left|u-u_{d}\right|^{2} D_{d}}{2 \sigma_{d}} \geq C_{b 1}
$$

where $\sigma_{d}$ is the surface tension and $C_{b 1}$ is an empirical coefficient having a value in the range 3.5 to 8.3 . The stripping separation happens when the proportion of Weber number to Reynolds number proportion achieves an edge esteem given by the condition:

$$
\frac{W e}{\sqrt{R e_{d}}} \geq C_{s 1}
$$

where Cs1 is a coefficient with the value 0.5 . The effect of particles, beads or rises on unbending strong surfaces may create a wide assortment of outcomes, as indicated by the size, speed and material of the affecting components and the idea of the surface. Beads may follow, skip or break; and the fluid stored superficially may hold its drop frame or converge into a fluid film. In this work bouncing back of beads from the divider is accepted to decrease computational exertion.

\subsection{Combustion modelling}

So as to about vicinity the diesel gas direct a surrogate gasoline n-Dodecane has been utilized as gas. because the fuel houses like thickness, consistency, express warm temperature and dispersal trade concerning weight and temperature, the records from TRC thermodynamic hand ebook has been carried out. here the affiliation of bodily parameters concerning temperature and weight had been given. customer depicted FORTRAN subroutines were applied inside the CFD code to cope with these combos. For appearing, often essential to start the reaction with the useful resource of displaying a start shape. This consists of one of 
the going with options:(i) reducing the fuel mass detail with the useful resource of a customer indicated detail in the begin district of the game-plan space. The reduced fuel mass piece is a shrewdness that requirements the manner that a chunk level of the gasoline has as of overdue been scorched by means of the use of the start fragment and is all subjects taken into consideration number one to start out the start engendering system. (ii) Introducing a run of the mill fire temperature in the begin vicinity. The begin strategy is proceeded certainly a customer decided on amount of emphasess or time undertakings, after which normal expending indicating renowned manage inside the begin district.

start is appeared by the usage of ECFM-3Z expending version. This model is fitting for non-homogeneous premixed begin and uses the unforeseen everyday shape. This model is set up for reenacting the mind boggling contraptions of harsh mixing, fire development dispersing and threatening substance spread that delineate modern-day interior devouring vehicles. The ' $3 Z$ ' addresses the zones of blending, to be particular the unmixed gasoline area, combined gases area and unmixed air however EGR region. The expending cannot manifest in unmixed gas and unmixed air area and in the long run it's far identified to take region just in the mixing vicinity. The three zones are too little to even recollect middle of the night bear in mind being in any manner settled with the aid of the paintings and are therefore displayed as sub-arrange aggregates. The mixed location is the postponed end result of incensed however atomic mixing among gases inside the extraordinary zones and is the find the start occurs. The mass divisions of species inside the combined vicinity may be portrayed due to the fact the components unanticipated midpoints:

$$
Y_{i}^{m}=Y_{i Z=Z_{m}}=\int_{\delta v} Y\left(x^{\prime}, t\right) \delta\left[Z\left(x^{\prime}, t\right)-Z_{m}\right] d V^{\prime}
$$

Where the subscript $\mathrm{m}$ indicates the blending zone, is the mean blend division and $d$ the Dirac work. All species in ECFM-3Z are adapted in this zone. The other two zones are described by the fuel in the unmixed fuel zone and the species in the unmixed air in addition to EGR zone. Anyway as a rearrangements, just oxygen is settled for in the last zone and every single other species are arithmetically identified with it.

\subsection{NOxmodelling}

As the diesel engine works under oxygen rich condition, with both premixed and dispersion ignition stages there is dependably an issue of NOx in these engines. Since the time scales for NOx responses are bigger than the time scales for the tempestuous blending process which again controls the ignition procedure, the NOx calculation is de-coupled from the principle responding stream field forecasts. Three distinct instruments have been distinguished for the development of nitric oxide amid the burning of hydrocarbons, in particular Thermal NOx, provoke NOx and fuel NOx. Warm NOx is shaped by high temperature oxidation of air nitrogen. For warm nitric oxide, the chief responses are commonly perceived to be those proposed by the accompanying three expanded Zeldovich system

$$
N_{2}+O \underset{k_{1}}{\rightleftharpoons} \mathrm{k} O+N
$$

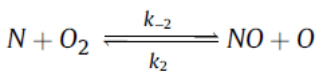

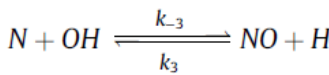

The rate constants for these reactions have been measured in numerous experimental studies and they are reported below:

$$
\begin{gathered}
K_{1}=1.8 \times 10^{11} \exp \left(\frac{-38370}{T}\right) \mathrm{m}^{3}(\mathrm{kgmol})^{-1} \mathrm{~s}^{-1} \\
K_{-1}=3.8 \times 10^{10} \exp \left(\frac{-425}{T}\right) \\
K_{2}=1.8 \times 10^{7} \mathrm{Texp}\left(\frac{-4680}{T}\right) \\
K_{-2}=3.8 \times 10^{6} \mathrm{Texp}\left(\frac{-20820}{T}\right) \\
K_{3}=7.1 \times 10^{10} \exp \left(\frac{-450}{T}\right) \\
K_{-3}=1.7 \times 10^{11} \exp \left(\frac{-24560}{T}\right)
\end{gathered}
$$

\section{RESULTS AND DISCUSSION:}

the larger record involves degrees. in the essential degree numerical reenactment were facilitated with general chamber and the second measurement numerical preoccupations were driven adjusted chambers (2 mm, 2.five $\mathrm{mm}$, three $\mathrm{mm}$ and three.five $\mathrm{mm}$ digressive openings) for interfacing at a staggering hole measure at complete weight conditions. coming about areas talks around the aftereffects of numerical examinations finished with the ones modifications.

three.1. glide an area characteristics from CFD investigate

The principle clarification behind course of action of bowl in a chamber is to keep the imperativeness amidst the give up periods of weight stroke. while the tumbling and spinning vortices are wrecked in a degree chamber engine the weight is saved in bowl and chamber strategy. Spin is the colossal air development winning in a DI diesel engine.

for the reason that gas implantation is 230 bTDC ( 3470 aTDC) a plot of the speed move issue vectors close to the gas imbuement will supply an undeniable picture. Fig. 1 appears around the speed place from the numerical test on the mid flying machine of the bowl at three hundred bTDC (3300 aTDC). It through and through may be indisputable that the speed an area is vivacious for three. $5 \mathrm{~mm}$ hole and is apparently less energetic as the partition affirmation reduces. the 2.five $\mathrm{mm}$ starting grandstands insignificant speed among all chamber changes. This respect being not really better than conspicuous chamber. This demonstrates the occupying gaps made partners in structure up a comprehensive stream pace through enabling air to encounter the openings and rapidly forwardly letting in. as the chamber packs the got air the squish speed overwhelms the advancement amidst the fag stop of strain stroke. some time of air from the land a region of the chamber is obliged to explicitly into the bowl, which allows in structure up a better turn dispersal than give all the extra mixing. One huge impact of giving openings is the consistency of pace vectors

Blue Eyes Intelligence Engineering 
as may be seen plainly in Fig. 1b to 5e. The comprehensive air improvement will accomplish better exacerbation.

Fig. 2 plots the space settled exacerbation in the begin chamber. It tends to be unquestionable that the engine power displays a higher help for most of the load changes, with $2.5 \mathrm{~mm}$ void structure up a more grounded acknowledge conditions for what they are speed and consequently an unrivaled unevenness looked for after with the guide of 2.0, three and three.five mm openings. regardless, this animated unevenness isn't maintained eventually of the affirmation stroke and it thusly ends up comparable to the run of the mill load around 20 bTDC (3400) and when the gas implantation starts offevolved the disrupting impact degrees are decay than a comparative vintage load. regardless, insulting this the devouring is better in changed chambers. this is possible essentially due to extended uniform spin speed as can be irrefutably found in Fig. $2 a$ and b. The three.five $\mathrm{mm}$ starting ascents clearly from a few issue gets by from the adjustments with most noteworthy basic inspiring power in turn pace. on the proportionate time as the point of convergence of the turn is kind of on the inward for the changed chambers with openings 2, 2.5 and three $\mathrm{mm}$. the standard chamber and $3.5 \mathrm{~mm}$ case have their turn focuses neutralized the chamber pivot. this may accomplish better savage shear near the divider districts and growth the shot of blended specks moved to the open entryway part of the bowl acknowledging film improvement. A plot generally the normal progress will supply more data around exceptional components of vaporization of fuel. Fig. 3 demonstrates the plot of fuel vaporization against wrench factor.

The firm measure of gas pervaded is $32.7 \mathrm{mg}$. Fig. three shows the standardized estimations of scattered fuel vapor. It by and large can be clear from Fig. 3 that the dissipating of fuel is quicker in $2.5 \mathrm{~mm}$ taking off chamber with the standard chamber (HCC) acting most reduced estimation of vanished gas. exactly when the chamber came to TDC (360 ) the immovable scattering through $2.5 \mathrm{~mm}$ void chamber is $70 \%$ of the embedded gas. Of this $60 \%$ fuel has profited by and essentially $10 \%$ of fuel stays as certified inside the watch. This $2.5 \mathrm{~mm}$ starting chamber is trailed by using the use of 3.five mm gap chamber with dissipating superior to base chamber and lower than $2.5 \mathrm{~mm}$ chamber.

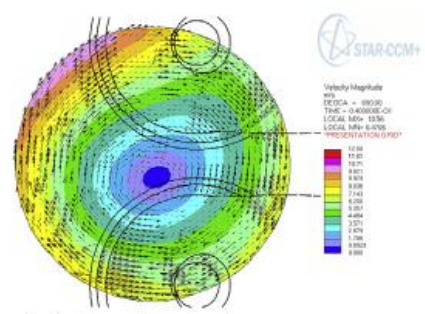

(a) Standard piston

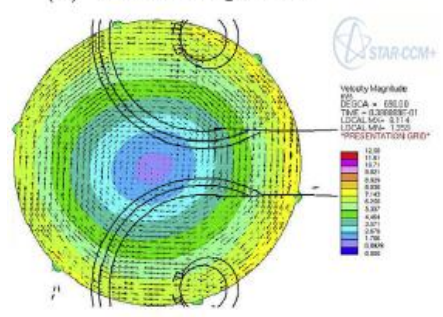

(b) $2 \mathrm{~mm}$ hole

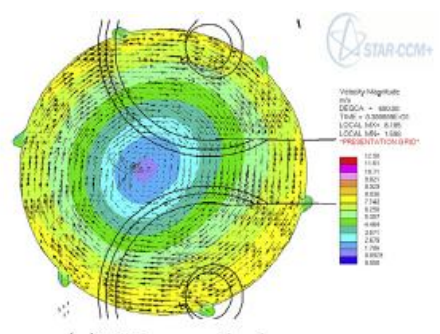

(c) $2.5 \mathrm{~mm}$ hole

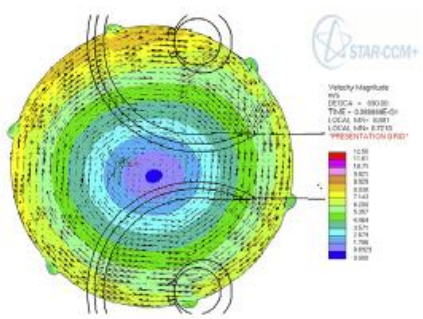

(d) $3 \mathrm{~mm}$ hole

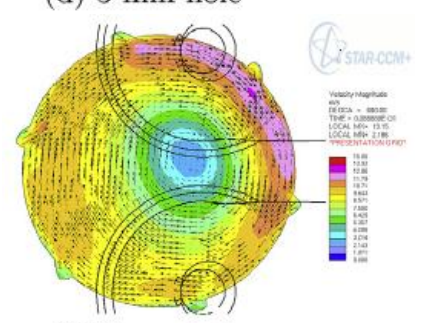

(e) $2 \mathrm{~mm}$ hole

Fig. 1.Comparison of simulated values of velocity field at the mid plane of the piston bowl at $30^{\circ} \mathrm{bTDC}\left(330^{\circ}\right)$.

When the cylinder achieved $10^{\circ}$ after TDC $\left(370^{\circ}\right)$ practically $90 \%$ of the dissipated fuel has been as of now consumed. At this wrench edge alternate cylinders including the base cylinder arrangement demonstrating some amount of dissipated fuel.

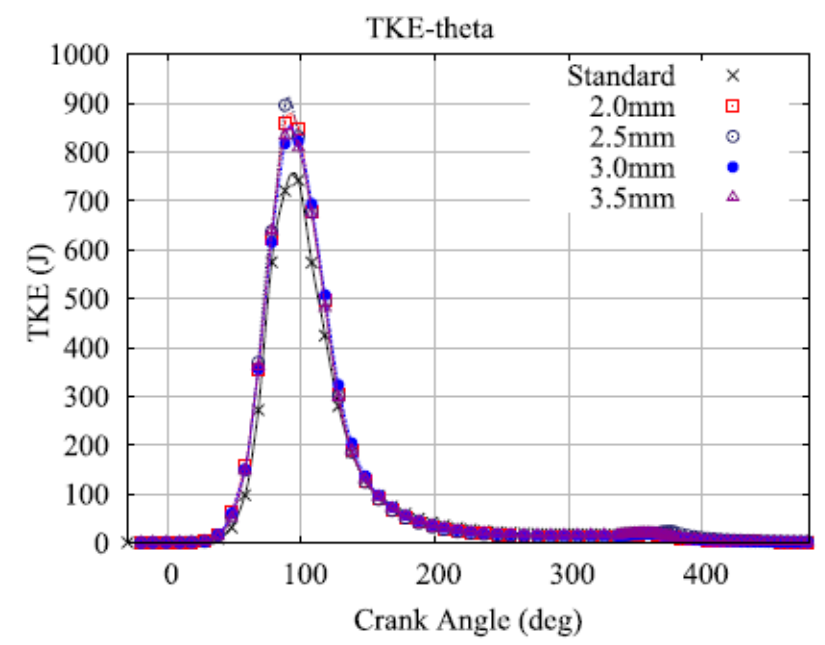

(a) Turbulent Kinetic Energy 


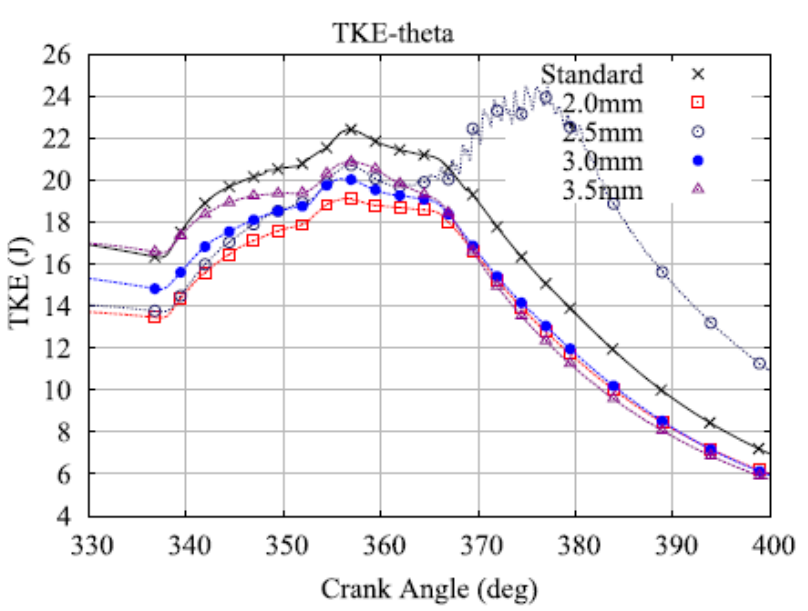

(b) TKE during Main Combustion

Fig. 2. Comparison of turbulent kinetic energy for the four piston configurations.

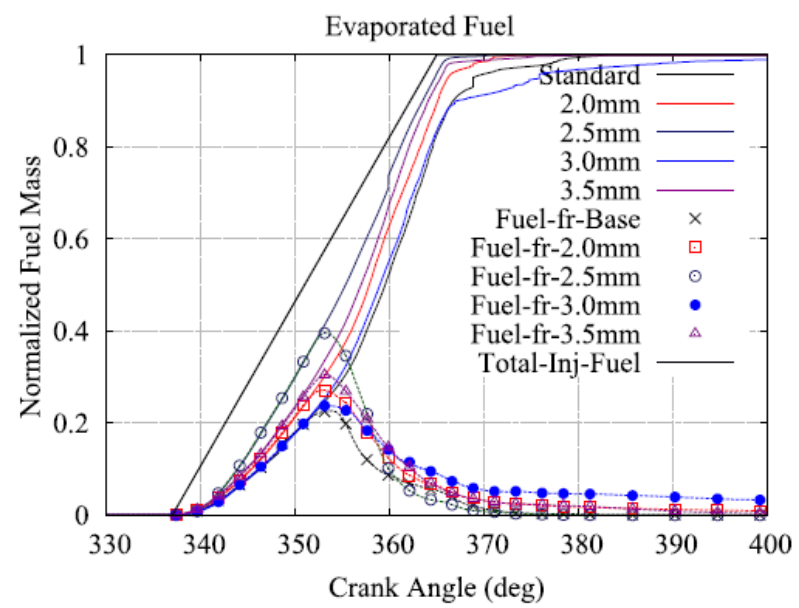

Fig. 3. Temporal evolution of total amount of fuel vapourised and fuel vapour still present in the engine cylinder.

\subsection{Combustion characteristics from CFD investigation}

In the past segments the stream field variety because of cylinder geometry and fuel infusion has been considered and it was discovered that the $2.5 \mathrm{~mm}$ opening cylinder gives a superior vanishing and ignition. This should result in higher warmth discharge rate and higher in-cylinder temperature.

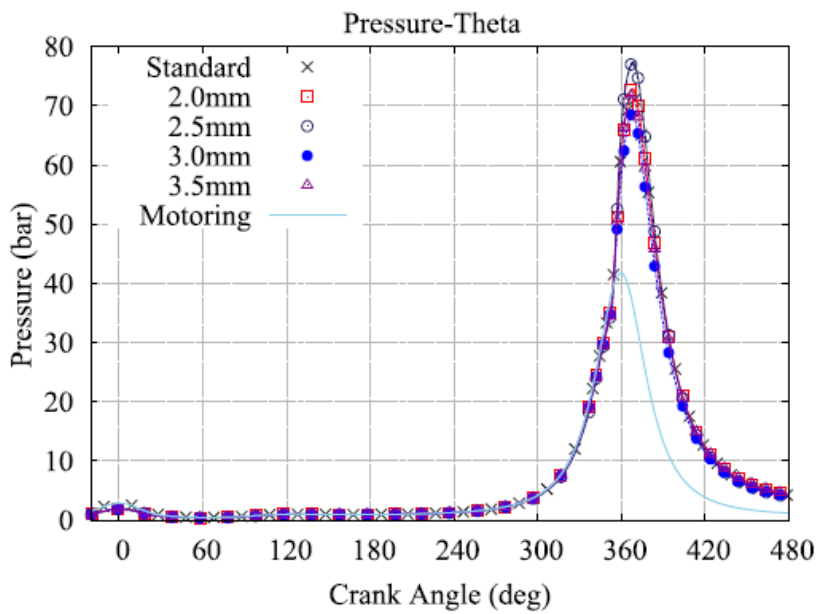

(a) Pressure

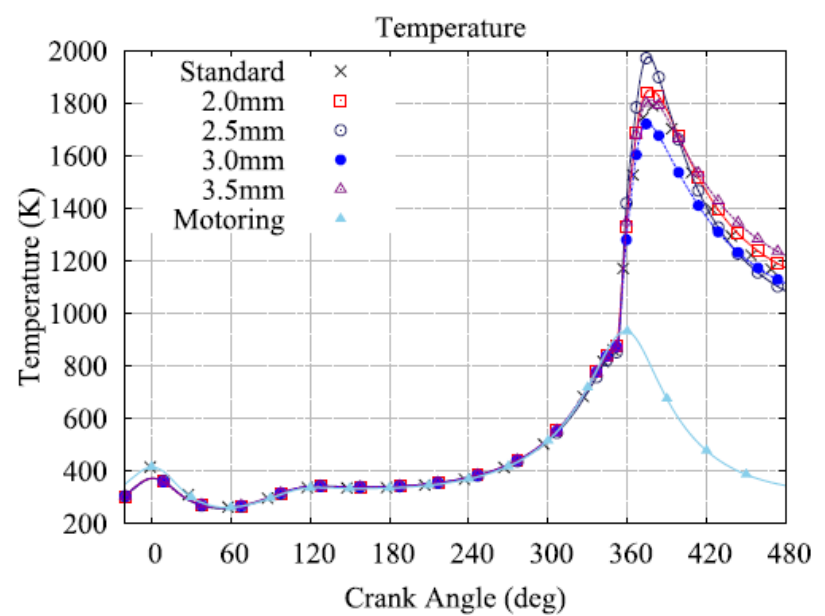

(b) Temperature

Fig. 4. Temporal variation of pressure and temperature for the piston variants

Fig. 4 demonstrates the quick grouping of weight and temperature for the exclusive changes. it may be visible that the $2.5 \mathrm{~mm}$ gap chamber skip on the maximum astounding weight searched for after with the aid of the usage of 2.0 and three. $5 \mathrm{~mm}$ chambers. As located inside the flow location and the dimension of vanishing it's far easy the $2.5 \mathrm{~mm}$ beginning chamber skip on a dominating expending confirmed up contrastingly in connection to alternate chambers. notwithstanding the manner in which that the turn velocity of different chambers $2.0 \mathrm{~mm} 3 \mathrm{mmand} 3.5 \mathrm{mmare}$ extra essential than $2.5 \mathrm{~mm}$, it does now not bring about the all-encompassing vanishing. this may in like manner be a direct outcome of the vanished mass of gas vapor and air caught inside the openings and does now not proportion on an critical measurement start or perhaps it might be moreover an aftereffect of the late expending of were given mass of vapor investigating poor start. warm temperature discharge fee count on an essential work in the improvement of weight and improvement of transmission from the motor. Fig. five indicates the plot of warmth discharge price for the various chamber blueprints. three obviously indisputable timetables are positioned within the plot. The premixed compose till 50 bTDC (3550) for all the indisputable chamber assortments, the scattering prepare from $50 \mathrm{bTDC}$ to 150 aTDC (3550 to 3750 ) and past due expending level after one hundred fifty CA after TDC. It is probably seen that the glow launched with the aid of way of the two.5 mm setting up chamber is most incredible at a hundred twenty $\mathrm{kJ} / \mathrm{m} 3$-deg which happens spherical 50 bTDC (3550 CA). at once the gleam discharged by means of the use of the same antique chamber is $20 \mathrm{~kJ}$ lower than $2.5 \mathrm{~mm}$ hole chamber. The shine fee through 2.0, 3.0 and 3.five $\mathrm{mm}$ chambers are really round $40 \mathrm{~kJ}$ lower than the two. $5 \mathrm{~mm}$ hole chamber. this is the reason that the burden and temperature are most lovable in $2.5 \mathrm{~mm}$ hollow chamber. The dissipating begin is in like way constantly overpowering in 2.five $\mathrm{mm}$ 


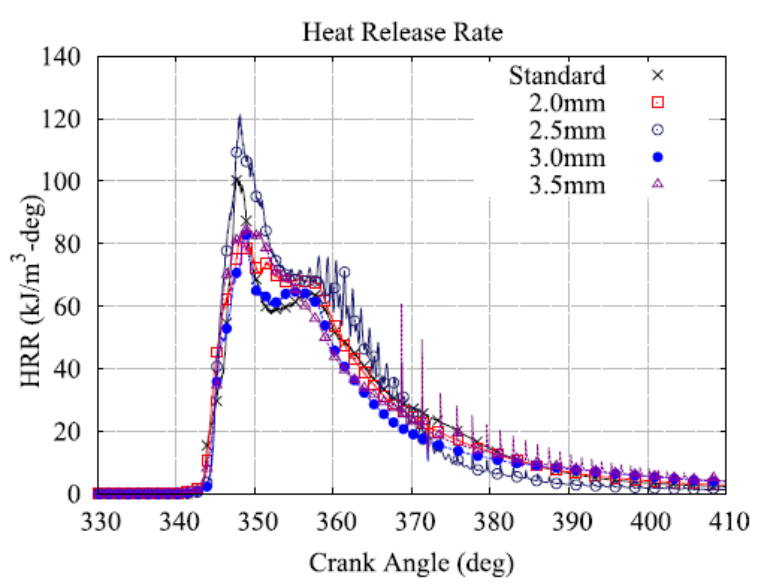

Fig. 5.Heat release rate for the three piston configurations.

beginning chamber which demonstrates extra extent of warmth inside the dispersing level showed up contrastingly in connection to obvious chamber plans. while the chamber achieves a wrench part 150 after TDC (3750) the spread devouring by the standard chamber overwhelms exchange chambers 2.zero and $3 \mathrm{~mm}$ chambers meanwhile as 2.five $\mathrm{mm}$ and three. $5 \mathrm{~mm}$ chambers propose wild developments in dispersing begin affirmation. Hinting Fig. four it will as a rule be seen that the 3.five $\mathrm{mm}$ separate transversely over structure up has fuel speed at $17.5 \mathrm{~m} / \mathrm{s}$ veered from a speed of eleven $\mathrm{m} / \mathrm{s}$ for the 2.five $\mathrm{mm}$ opening chamber. that is a decision of fifty nine\% in gas volume stream into, which shows the affirmation that anyway the spin and tumble increments for those progressions it extra than balances the cleft impact made by using the begin occuring in those territories.

Fig. $6 \mathrm{c}$ and $10 \mathrm{~d}$ displays the examination of begin delay and expending period for the different chamber courses of action. The expending range is settled from meanwhile as the weight starts offevolved turning out badly from the motoring bend and surrender of begin is well-known to had been come to at even as ninety five $\%$ of the spread gas has been eaten up. Fig. $6 \mathrm{a}$ and $10 \mathrm{~b}$ thinks generally the start of expending, stop of begin, start deferral and devouring period for the contrasting chamber plans. It tends to be discovered the weight as noted in Fig. 6a for all the blend models have a decrease an inspiration than the motoring weight after the beginning of gas imbuement at 23 bTDC (3370). This clearly demands with the way in which that the embedded gas keeps heat from the motor chamber for dissipating and consequently the weight is decay than the motoring an inspiration until the beginning of begin. the start of begin is in a general sense established on different feelings like transparency of mix inner unsteadiness limit, adequate incitation control and the time predicted to finish the ones conditions. It very well may be seen that the most extraordinary broadened begin dispose of is done by using the use of $2.5 \mathrm{~mm}$ starting chamber looked for after by using three. $5 \mathrm{~mm}$, three $\mathrm{mm}$, upscale chamber and a few $\mathrm{mm}$ hole chamber. since the start dispose of is extended there's a higher transparency of mix organized to eat up. for the reason that start delay for two.five $\mathrm{mm}$ chamber is the most drawn out there can be extra extent of premixed rate which prompts it doing most noteworthy unmistakable weight. thiswill also be move checked with the gleam discharge plan as available in Fig. 5 wherein the warm temperature discharged by techniques for the two.five $\mathrm{mm}$ hole chamber is commonly indispensable. one of the clarification in the again of the decrease start delay for the $2.5 \mathrm{mmhole}$ chamber might be the higher scattering of vanished fuel and subsequently lesser time expected to get ready blend inside the combustibility routine. A similar thinking can likewise be ascribed to $3.5 \mathrm{~mm}$ opening cylinder where the start delay is next higher. The ignition span is likewise the most reduced for

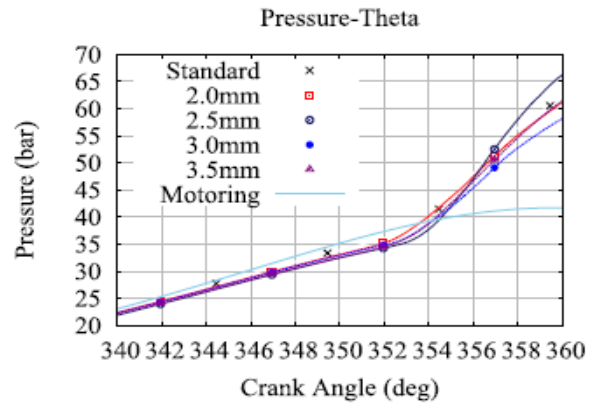

(a) Start of Combustion Burned Percentage of Fuel

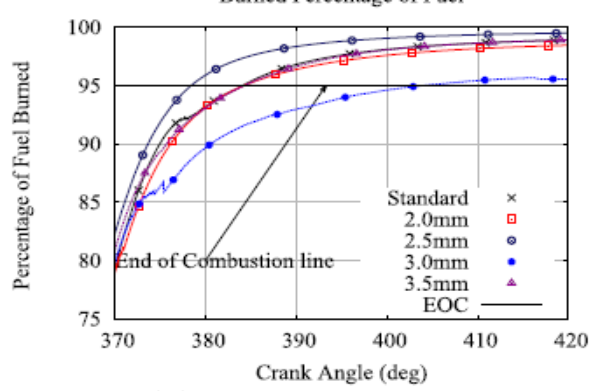

(b) End of Combustion

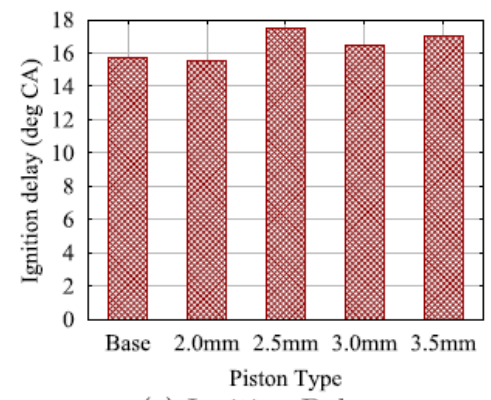

(c) Ignition Delay

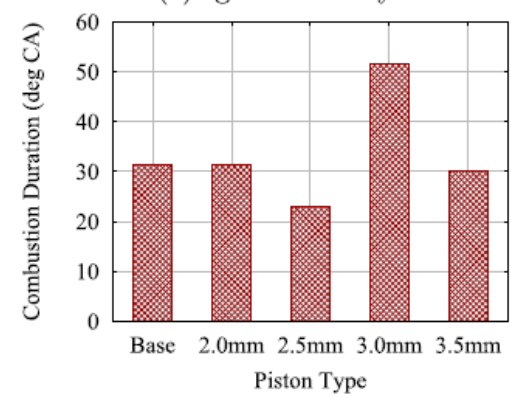

(d) Combustion Duration

Fig. 6.Comparison of start of combustion, end of combustion, ignition delay and combustion duration. 


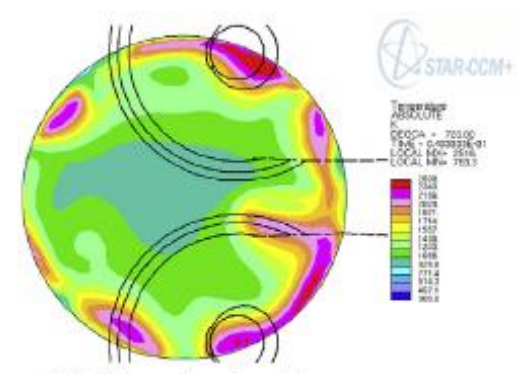

(a) Standard piston

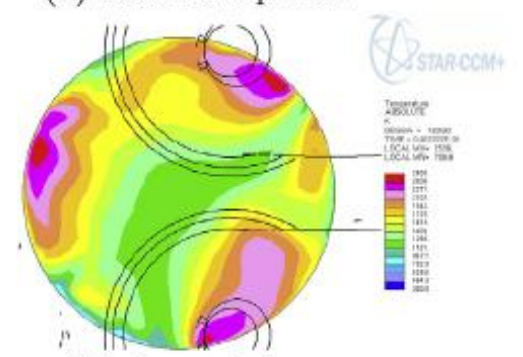

(b) $2 \mathrm{~mm}$ hole

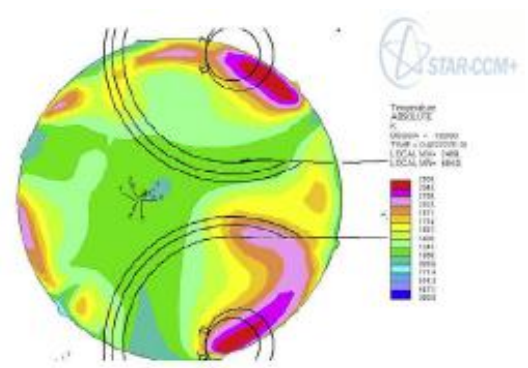

(c) $2.5 \mathrm{~mm}$ hole

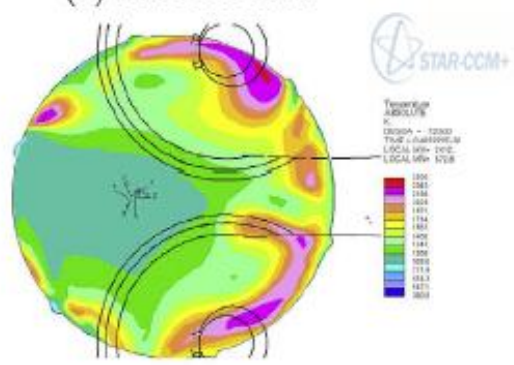

(d) $3 \mathrm{~mm}$ hole

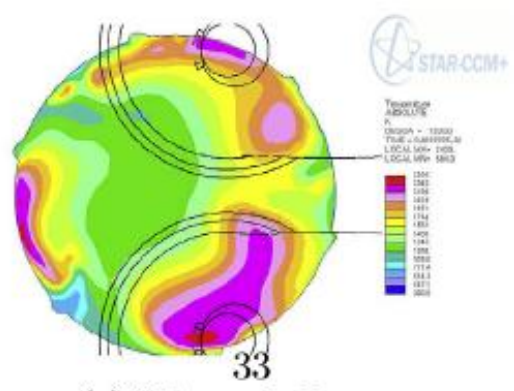

(e) $3.5 \mathrm{~mm}$ hole

Fig. 7.Comparison of temperature at a plane passing through the middle of the bowl at TDC $\left(360^{\circ}\right)$.

$2.5 \mathrm{~mm}$ commencing chamber looked for after thru three. $5 \mathrm{~mm}$ chamber. on the off hazard that better spin associated with changed chamber permits in better scattering of the vapor, through then that might have finished the maximum raised weight flow with the aid of the three. $5 \mathrm{~mm}$ chamber searched for after by using way of $3 \mathrm{~mm}$ chamber. in any case, for this case that the $3 \mathrm{~mm}$ chamber passing on maximum insignificant weight maximum simple expending duration. one of the motive might be that on the off threat that higher mass of vanished gas receives trapped into the opened openings, it might bring about divider extinguishing and higher leftovers transmission. this will in like manner be a proper away aftereffect of the way that the open door volume of the alternate increments and this is meditated within the weight diploma. This indicates the lower in execution for the unintentional gaps past 2.five mm hollow width has greater to do with hollow quantity made as digressive openings, which connects more air inside the gaps which expands the divider extinguishing effect of embedded dabs. This effects in decrease execution past 2.5 $\mathrm{mm}$. brushing off the direction that there may be a dominating air improvement in all of the modified chambers the sick-disposed impact of divider soaking or divider movie improvement inside the openings extra than counterbalances focal points totaled in angle on higher air improvement. The spread example of the changed chambers will supply a pervasive recognition into the theories simply referenced right here.

3.three. Execution of the engine with adjusted chambers

Fig. eight examines the brake warmness functionality and wrench factor settled weight consequences of examinations did on the balanced chambers. $2.0 \mathrm{~mm}, 2.5 \mathrm{~mm}$ and three.zero $\mathrm{mm}$. The distinction inside the chamber fabricates the start adequacy as which leads to extended apex weight regards for $2 \mathrm{~mm}$ and 2.five $\mathrm{mm}$ chambers. Regardless, the equal cannot be seen with $3 \mathrm{~mm}$ chamber which has a lower zenith weight. From the theoretical examinations the balanced chambers with $2 \mathrm{~mm}$ and $2.5 \mathrm{~mm}$ holes outfit an stepped forward brake warm viability with a selection of $1 \%$ and multiple $\%$ independently for the two $\mathrm{mm}$ and a pair of.five mm holes chambers at $80 \%$ weight. Regardless, the three mm taking off chamber makes a lower estimation of warmth viability stood out from the same old chamber. on the equal time because the progressions with $2 \mathrm{~mm}$ and more than one. $5 \mathrm{~mm}$ manufactures the opportunity quantity, it could bring about a lower estimation of heat capability. however, regardless of what may be normal it extends it's heat performance with the aid of the usage of approximately $2 \%$ at $80 \%$ of the stack. A comparative reasoning need to starting superb with the $3 \mathrm{~mm}$ hollow chamber.

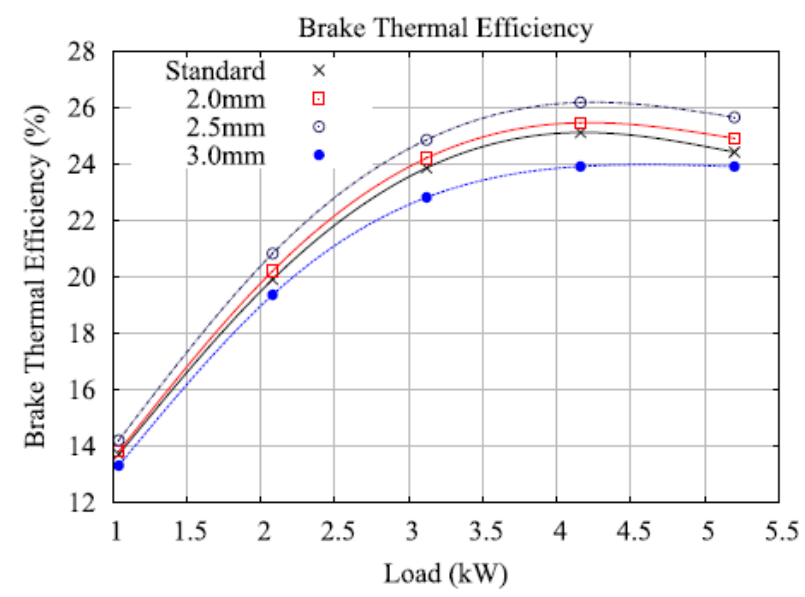

(a) Brake Thermal Efficiency 


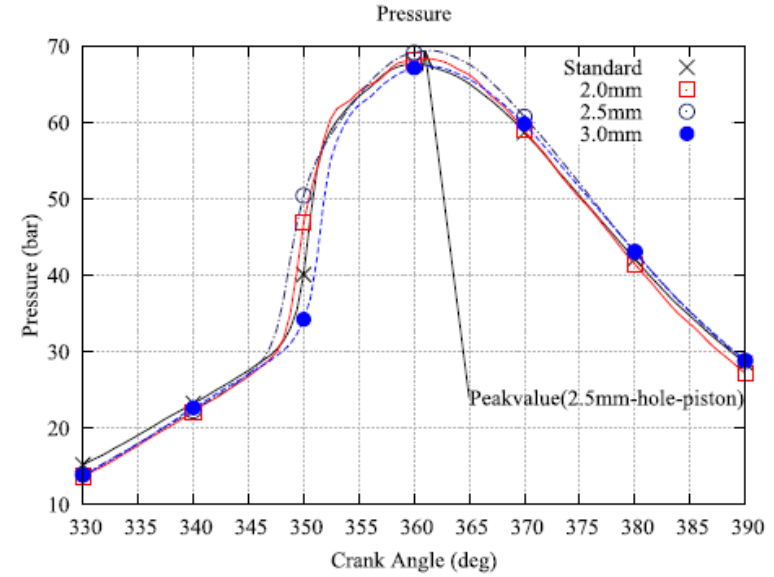

(b) Pressure Vs Crank Angle

Fig. 8. Comparison of brake thermal efficiency at various loads and crank angle resolved pressure.

\section{CONCLUSION}

Numerical multiplications are coordinated with slick and changed cylinders with digressive openings inside the cylinder with separations all through $2 \mathrm{~mm}, 2.5 \mathrm{~mm}$, three $\mathrm{mm}$ and 3.five $\mathrm{mm}$. A segment of the main finishes are:

- The incidental openings inside the cylinder improves air movement inside the cylinder empty. The improvement in whirl at the period of fuel implantation (3360 aTDC) is round $11 \%$ for $2 \mathrm{~mm}, 2.5 \mathrm{mmand} 3 \mathrm{~mm}$ cylinder gaps in the meantime as the three. $5 \mathrm{~mm}$ digressive opening upgrades the twirl through about $805 \%$.

- the two.5mm empty cylinder has better level of gas vapor at forty\% of gas appeared differently in relation to the next beginning sizes and general cylinder that have $20 \%-25 \%$ of mass disappeared on the period of beginning of start.

- the $2.5 \mathrm{~mm}$ starting cylinder has better warmth release accuse differentiated of unique cylinder sorts.

\section{REFERENCES}

1. Cowland C, Gutmann P, Herzog P. Traveler vehicle Diesel Engines for the U.S. SAE Technical Paper, 2004-01-1452. 2004. http://dx.doi.org/10.4271/2004-01-1452.

2. Dehong Z, Hill P. impact of whirl on ignition in a fast tube shaped chamber. Combust Flame 1996;106(3):318e32. http://dx.doi.org/10.1016/0010-2180(ninety five)00256-1.

3. Cao L, Bhave A, Su H, Mosbach S, Kraft M, Dris M, et al. affect of infusion timing and cylinder bowl geometry on diesel percent. burning and discharge (2009-01-1102) SAE Int J Engines 2009;1(2):1019e33. 